\title{
La musealización del Castell de Castalla (España): la realidad que pudo ser y no será
}

The musealisation of Castalla Castle (Spain): a project that could have been possible

\author{
Juan Antonio Mira Rico ${ }^{a}$, Màrius Bevià i Garcia ${ }^{b}$, José Ramón Ortega Pérez ${ }^{c}$ \\ ${ }^{a}$ Universitat Oberta de Catalunya / ICOMOS-ICOFORT, Castalla, Spain, mirarico@ hotmail.com \\ ${ }^{\mathrm{b}}$ Architect, Sant Joan d'Alacant, Spain, mariusbg@gmail.com \\ ${ }^{\mathrm{c}}$ Arpa Patrimonio, Sant Vicent del Raspeig, Spain, arpaoscu@ gmail.com
}

\begin{abstract}
Between 2009 and 2017, the "Castalla Castle Heritage Site Social Regeneration Project" was executed with the aim of managing its entire cultural and natural heritage. Castalla Castle was one of the basic pillars of this project, and therefore its musealisation began in 2016. In this way, the fortification was equipped and included some contents that made the visit more attractive. The abrupt termination of this social regeneration project made it impossible to continue with its musealisation, as originally planned. Thus, this paper will explain the proposals that were intended to be carried out in three parts -Palau (Palace), Pati d'Armes (Lower Ward) and Torre Grossa (Large Tower)- in order to enrich the limited offer of musealised fortifications in the province of Alicante and turn Castalla Castle into a reference.
\end{abstract}

Keywords: Castalla Castle, castles, musealisation, province of Alicante.

\section{Introducción}

En 2016, como parte del Proyecto de recuperación social del Conjunt Patrimonial del Castell de Castalla (2009-2017), se inició la musealización de la fortificación (Fig. 1), que tuvo continuación el año siguiente. Como se ha puesto de manifiesto en anteriores trabajos (Mira, Bevi, Ortega, 2017, 2018); dicha actuación se centró en el Palau (1362-siglo XV), una de las tres partes principales del castillo. Y, en concreto, en su cuerpo de guardia, patio y despensa.

Teniendo en cuenta que en la provincia de Alicante existen, en la actualidad, cincuenta y siete fortificaciones públicas y privadas y que solo diez de ellas -Atalaya (Villena), Banyeres de Mariola, Castalla, Cocentaina, Dénia, Guardamar del Segura, Penella (Cocentaina), Petrer, Santa Bárbara (Alicante) y Sax-; se encuentran, de manera completa y/o parcial, musealizadas (Mira, 2017, pp.
210-213; Mira, Bevià, Ortega, 2017, p. 428), se entiende la importancia de la actuación desarrollada en el Castell de Castalla.

En este estudio, se describirán las características de la musealización que se pretendía llevar a cabo en las partes de la fortificación que no lo estaban -Palau (palacio): cocina, primera y segunda planta; Pati d'Armes (patio de armas) y Torre Grossa (torre gruesa)-. Una iniciativa que, aunque imposible de realizar, apostó, de manera decidida y siguiendo los planteamientos de diversos autores como C. Martín Piñol y J. Castell Villanueva (2010), J. Santacana i Mestre (2010) y J. Santacana i Mestre y F. X. Hernàndez Cardona (2011, pp. 253-268); por una musealización interactiva y didáctica con secciones especializadas de interactivos (SEI). Este planteamiento, innovador, en el contexto de la provincia de Alicante, contrasta la 


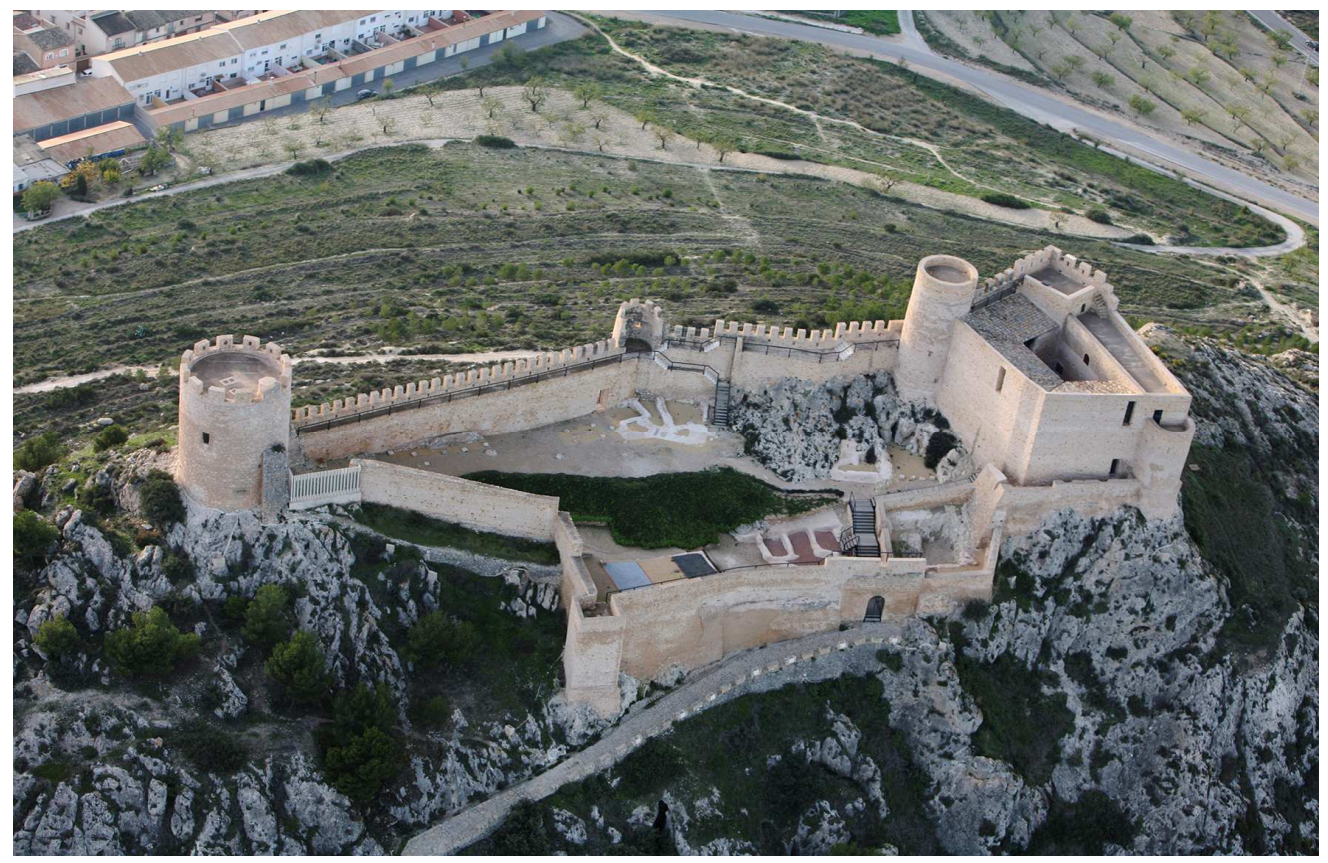

Fig. 1. Castell de Castalla: la Torre Grossa (i), el Pati d'Armes y el Palau (J. A. Mira Rico, M. Bevià i Garcia, J. R. Ortega Pérez, 2017, 2018).

intervención tradicional (es decir, no interactiva y didáctica), desarrollada por el nuevo equipo encargado de la musealización del castillo (Rey, Belsanz, Hortelano, 2018).

\section{La musealización del Castell de Castalla}

\subsection{Antecedentes}

Tras la recuperación arquitectónica del castillo, entre 2003 y 2006, se consiguió un continente sin contenido. Por ello, el siguiente paso lógico era abordar su musealización. No obstante, dicha intevención no pudo realizarse por varias razones. En primer lugar, porque era imprescindible estudiar en detalle y publicar los resultados de las actuaciones arqueológicas y arquitectónicas ejecutadas hasta la fecha. En segundo lugar, porque era necesario llevar a cabo nuevos trabajos para mejorar aspectos desconocidos o poco conocidos. Caso, por ejemplo, de los análisis antracológicos, de madera y de fauna, localizados en el Palau y el Pati d'Armes, de una investigación documental más exhaustiva, o de conocer asentamientos arqueológicos relacionados con el castillo, caso de la vila medieval o de la necrópolis andalusí de Almarra. Y, todo ello, con el objetivo de tener una mejor comprensión global de la fortificación y su territorio. Finalmente, y como última razón, había que sumar la reticencia del Ayuntamiento de Castalla a seguir invirtiendo recursos económicos en la fortificación una vez completada la recuperación arquitectónica.

Ante esta situación, en primer lugar, se diseñó un programa de visitas guiadas y se publicó una guía de visita (Mira, 2012), con unos contenidos mínimos, que permitiesen afrontar la demanda social por visitar el castillo. A continuación, a partir de 2009, se implementó el Proyecto de recuperación social del Conjunt Patrimonial del Castell de Castalla que permitió, entre otras cuestiones, implementar un modelo de gestión integral de todo el patrimonio cultural y natural situado en el mismo (Mira, 2016; Mira, Bevià, Ortega, 2015), profundizar en el conocimiento de la fortificación y de yacimientos arqueológicos afines y cubrir lagunas de conocimiento (Menéndez, et al., 2010; Mira, Bevià, 2016; Mira, et al., 2016, 2017). A medida que los trabajos de investigación, conser- 
vación, didáctica y difusión se desarrollaban, en 2012 se elaboró un proyecto museográfico de todo el castillo del que se publicó un resumen en 2017 (Mira, 2017). No obstante, su inicio se demoró hasta 2016, momento en el que el Ayuntamiento de Castalla decidió apostar por la misma. Teniendo en cuenta el coste económico de la misma, se optó por realizarla por fases, siendo el Palau la primera zona elegida por su buen grado de conocimiento y porque poseía varias estancias que podían ser, fácilmente, musealizadas. De esta manera, se comenzó por el cuerpo de guardia en el que se instaló un equipamiento museográfico cuya función es la de servir a los visitantes, de espacio introductorio para conocer el conjunto patrimonial y la fortificación (Fig. 2). Sus características fueron detalladas en un trabajo reciente (Mira, Bevià, Ortega, 2017). No obstante, y de manera resumida, se trata de una unidad expositiva que, bajo el tema El Conjunt Patrimonial del Castell de Castalla, una puerta abierta hacia su pasado, engloba las siguientes subunidades expositivas: 1) La fortificación como parte del Conjunt Patrimonial del Castell de Castalla, 2) Conjunt Patrimonial del Castell de Castalla, 3) La configuración del Castell de Castalla es...singular, 4) ¿Qué se conserva de sus distintas fases?, 5) ¿Cuál fue su papel histórico?, 6) Pasos para su recuperación y 7) Para saber más.

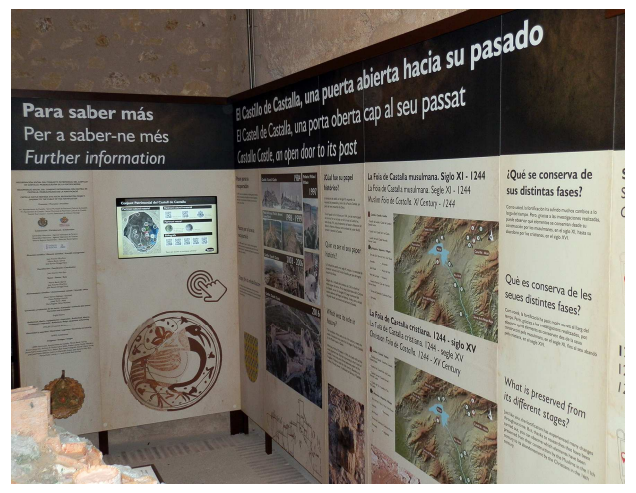

Fig. 2. Vista del montaje expositivo en el cuerpo de guardia (J. A. Mira Rico, M. Bevià i Garcia, J. R. Ortega Pérez, 2018).

Además, cada una de dichas subunidades tiene unos contenidos que cumplen con una serie de objetivos, mediante el empleo de diversos recur- sos museográficos, interactivos y no interactivos, y no museográficos (Mira, Ortega, Bevià, 2018, p. 1310).

En 2017, se musealizaron el patio del Palau y del almacén/despensa (Mira, Bevià y Ortega, 2018). Del patio se explicaron sus características mediante "[...] un módulo didáctico de categoría gráfica $[. .$.$] con información escrita con un voca-$ bulario sencillo y lejos de tecnicismos y con textos cortos y precisos en castellano, valenciano e inglés, alineados a la izquierda para facilitar su lectura. Asimismo, al tratarse de un espacio exterior, el diseño del módulo (apostó) por los fondos oscuros y las letras claras, al contrario que en el cuerpo de guardia, más fáciles de leer" (Fig. 3) (Mira, Ortega, Bevià, 2018, p. 1312). En el almacén/despensa, teniendo en cuenta sus características arquitectónicas, se instaló "[...] un módulo expositivo formado por la combinación de cuatro módulos didácticos distintos, pero complementarios entre sí (Fig. 4): recreación visual, audiovisual, táctil y gráfico [...]. De esta manera, se realizó una recreación visual del espacio a finales del siglo $\mathrm{XV}$, en el momento de esplendor del $\mathrm{Pa}$ lau. Fue una actuación innovadora, pues en ninguno de los castillos musealizados de la provincia de Alicante, se había ejecutado una intervención de semejantes características hasta la fecha" (Mira, Bevià, Ortega, 2018, p. 1313).

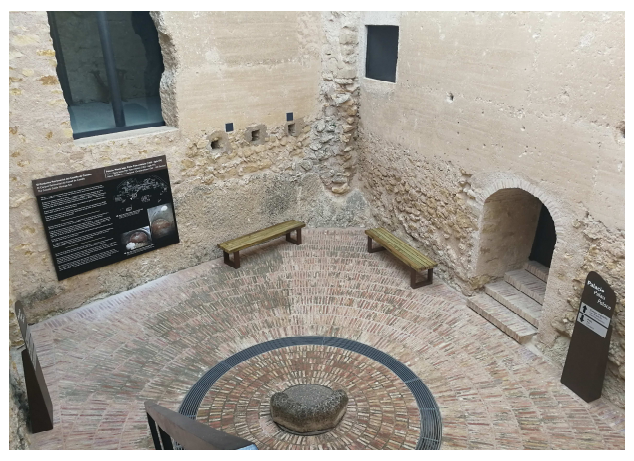

Fig. 3. Vista parcial del patio del Palau tras la intervención (J. A. Mira Rico, M. Bevià i Garcia, J. R. Ortega Pérez, 2018).

\subsection{Objetivos}

En este punto, sirven, perfectamente, los objetivos señalados para la intervención en el cuerpo de 
guardia (Mira Rico, Bevià i Garcia, 2017, pp. 427-434), el patio y el almacén del Palau (Rico, Bevià i Garcia, 2018, pp. 1310-1311).

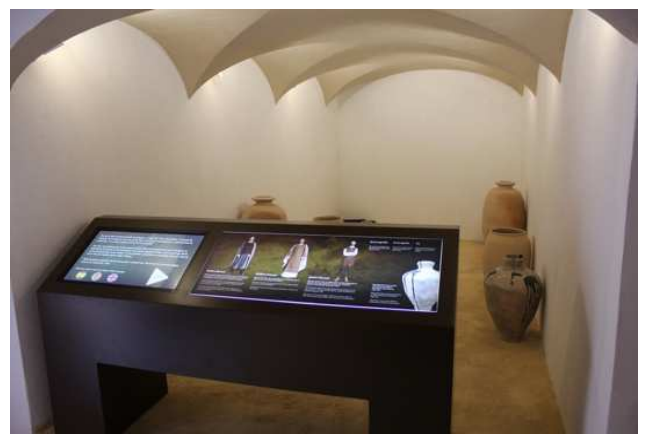

Fig. 4. Vista del almacén tras la instalación del módulo didáctico de recreación visual (Atelier Proyectos).

De esta manera, el objetivo general planteado era el de contribuir a la recuperación social del Conjunt Patrimonial del Castell de Castalla, a través de la musealización del castillo. En cuanto a los objetivos específicos destacan los siguientes: dotar al conjunto patrimonial de un potente equipamiento que permitiera conocer, a través de su musealización, la historia de la localidad y de la fortificación; mejorar la calidad del conjunto patrimonial y de la fortificación como producto turístico-cultural de enorme interés social; convertir la visita al conjunto patrimonial y al castillo en una experiencia agradable para los turistas y los visitantes, fomentando su participación activa, en la que pudieran disfrutar y aprender (tanto a nivel formal como no formal); dar a conocer los últimos avances científicos generados por el equipo que trabajaba en la recuperación social del conjunto patrimonial, en general, y del castillo, en particular; mejorar la oferta turística, de carácter cultural, local, comarcal, provincial y autonómica; y enriquecer, todavía más, el panorama de castillos musealizados en la provincia de Alicante convirtiendo la fortificación en un elemento destacado de dicha oferta-. A través de todos ellos, se buscaba dotar de contenido a un continente que carecía de él, acorde con lo expuesto en el Plan Nacional de Arquitectura Defensiva (Carrión, 2015) y con diversos ejemplos a nivel nacional, caso del Castillo de Peníscola (Castellón) o del Castillo de Lorca (Murcia), e internacional, caso del Castillo de San Jorge (Lisboa) o del Castillo de Dover (Mira, Bevià, Ortega, 2018, p. 1312).

\subsection{Planteamiento teórico}

Desde el primer momento se apostó por un modelo de musealización interactivo porque favorece el disfrute y el aprendizaje de la gente fuera de las aulas (Mira, 2017, pp. 215-216). Y, en concreto, se apostó por las secciones especializadas de interactivos (SEI), la segunda en grado de interactividad tras las instalaciones interactivas totales (IIT) y por delante de los dispositivos de interactividad dispersos (DID) e interactivos de información de general (IIG). El tipo escogido se caracteriza "[...] [por combinar] objetos originales; réplicas tocables y módulos interactivos [...]; [fomentar] la participación activa del visitante; [ser] accesible y didáctica [...] y [estar orientado] al público familiar [...] (Martín, Castell, 2010, pp. 95-99).

La misma se orientaría al público familiar, pero, también, incluiría a los escolares, estudiantes, colectivos con necesidades especiales y expertos. Este modelo es el ideal porque se aleja de la concepción tradicional de musealización y suponía una novedad respecto a los castillos musealizados de la provincia -básicamente tradicionales y con algún interactivo puntual-. Por ello, el proyecto formulado aspiraba a convertir al Castell de Castalla en la primera fortificación musealizada que apostaba, de manera decidida, por la interactividad. No obstante, y a diferencia de los SEI tradicionales, los interactivos en el castillo no se instalarían en salas especiales situadas a su entrada o salida, como es habitual en las musealizaciones del tipo SEI, sino que se integrarían en la propia exposición permanente. En este sentido, como las visitas a la fortificación están limitadas a un número determinado de visitantes por hora, debido a las dimensiones de la misma; no se correría el peligro de convertir sus salas en espacios ruidosos o espacios aglomerados -una de las principales desventajas de este tipo de interactividad, como bien han señalado Carolina Martín Piñol y Júlia Castell Villanueva (2010, pp. 95, 96). 


\subsection{Planteamiento conceptual}

Los contenidos se organizarían en torno a cinco grandes módulos expositivos -El Castell de Castalla, una puerta abierta hacia su pasado; La historia antes del castillo; Nacimiento y crecimiento del Castell de Castalla; Una nueva etapa en su vida; y El futuro-; cinco unidades temáticas Presentación 1; Presentación 2; Surgimiento del hịṣn (al-) qasțal·la /La transformación en castillo feudal/Los últimos momentos de esplendor; Un castillo que ya no funciona como tal; Un castillo que sirve para conocer nuestro pasado; La recuperación social del Castell de Castalla; y Del Castell de Castalla al Conjunt Patrimonial del Castell de Castalla-; diez unidades -El Castell de Castalla; El cerro, un espacio muy transitado; Visión de dos castallenses andalusíes: Muhammad de Alhoxex y Sorona; Visión del señor de Castalla: Ramon de Vilanova i Montagut ${ }^{1}$; Visión de Rodrigo Vélez de la Huerta y Juan de la Miel (constructores de la Torre Grossa); Abandono; Otros usos: atalaya militar, base escultórica y lugar de visita; Los primeros trabajos y las investigaciones en los años 80 del siglo XX; Actuaciones patrimoniales; y Un proyecto de futuro hecho presente y setenta subunidades expositivas.

Las actuaciones ejecutadas en las distintas partes del Palau, corresponderían a los módulos expositivos El Castell de Castalla, una puerta abierta hacia su pasado (cuerpo de guardia) y Nacimiento y crecimiento del Castell de Castalla (patio y almacén); las unidades temáticas Presentación (cuerpo de guardia, patio y almacén); las unidades expositivas El Castell de Castalla (cuerpo de guardia) y Visión del señor de Castalla: Ramón de Vilanova $i$ Montagut (patio y almacén/despensa); y las subunidades expositivas $L a$ fortificación como parte del Conjunt Patrimonial del Castell de Castalla, El Conjunt Patrimonial del Castell de Castalla, La configuración del Castell de Castalla es... singular, ¿Qué se conserva de sus distintas fases?, ¿Cuál fue su papel histórico?, Pasos para su recuperación y Para saber más (cuerpo de guardia), ¿Cómo era? El Palau y el Pati d'Armes (patio) y La vida cotidiana en el castillo: recreación del almacén/despensa, la cocina y en la torre circular del Palau (almacén).
Teniendo en cuenta lo señalado hasta el momento, a continuación, se describirán los módulos expositivos que no se han ejecutado o cuyas características no han sido publicadas con anterioridad (Mira, 2017). En este sentido, el módulo expositivo La historia antes del castillo, contaba con una unidad temática denominada Presentación y una unidad expositiva titulada El cerro, un espacio muy transitado. En el mismo se explicaría, en castellano, valenciano e inglés, que el cerro estuvo ocupado desde la Prehistoria (Edad del Bronce) y hasta la Edad Moderna de manera, prácticamente, ininterrumpida; se darían a conocer las principales características de los pobladores prehistóricos, iberos y romanos del cerro. Para ello se emplearía un módulo didáctico de categoría gráfica, con escenas que harían referencia a las gentes del bronce, iberas y romanas; un módulo didáctico de categoría gráfica y táctil sobre la Edad del Bronce y las épocas ibera y romana, respectivamente. Los textos se acompañarían de una serie de mapas en relieve con los principales yacimientos arqueológicos de la Edad del Bronce en la provincia de Alicante, de la Contestania y de Hispania, en la época del emperador Trajano (98117). También se emplearía un módulo didáctico de carácter audiovisual en el que se destacarían las condiciones geográficas y estratégicas que favorecieron la ocupación del cerro antes de la construcción del castillo. El mismo estaría, hablado y subtitulado, como el resto, en tres lenguas, para hacerlo más accesible a las personas que presenten, por ejemplo, una discapacidad auditiva. Finalmente, habría una vitrina accesible con objetos originales y reproducciones de la Edad del Bronce y las culturas ibera y romana, respectivamente. Las reproducciones, que serían tocables, estarían en el exterior de la vitrina.

El módulo expositivo Nacimiento y crecimiento del Castell de Castalla, diseñado para ser instalado en la primera planta del Palau, contaba con una unidad temática titulada Surgimiento del hișn (al-) qastal.la, relacionada con la unidad expositiva $\mathrm{Vi}$ sión de dos castallenses andalusíes: Muhammad de Alhoxex y Sorona. En la misma se presentarían, en tres idiomas, Muhammad de Alhoxex, $q \bar{a}$ 'dí del hișn (al-) qasțal la y su esposa Sorona (ambos deberán estar novelados pues, aunque existieron realmente, apenas se dispone de infor- 
mación sobre ellos); y dar a conocer la fase andalusí del castillo (siglo XI-1244). Para ello se utilizaría un módulo didáctico de carácter audiovisual, en el que se presentarían los dos personajes andalusíes. El mismo, de no más de cinco minutos de duración, se vería en una pantalla LED y, también, estaría hablado y subtitulado en tres lenguas. Otro módulo que se emplearía sería uno de categoría gráfica y táctil sobre la cultura andalusí. Los textos se acompañarían de una serie de mapas, en relieve, sobre el Sharq al-Andalus, con la taifa de Denia (siglo XI) y sobre el Sharq al-Andalus, con la taifa de València (siglo XIII). También habría un módulo didáctico de categoría informática y audiovisual, con pantalla táctil de grandes dimensiones. Su manipulación permitiría activar una pista de audio, en cualquiera de las tres lenguas citadas con anterioridad, en la que Muhammad o Sorona hablarían sobre el contenido seleccionado al tiempo que se proyectarían imágenes en una pantalla sobre cualquiera los contenidos relacionados con la cultura andalusí en Castalla. Todo se completaría con una vitrina accesible con objetos originales y reproducciones tocables de la época andalusí, que estarían en el exterior de la misma.

Otra unidad temática de dicho módulo era Los últimos momentos de esplendor, relacionada con la unidad expositiva Visión de Rodrigo Vélez de la Huerta y Juan de la Miel, constructores de la Torre Grossa. En la misma se presentaría a Rodrigo Vélez de la Huerta y Juan de la Miel, constructores de la citada torre. Como en el caso anterior, ambos deberán estar novelados ya que la información disponible sobre ellos es muy escasa. Para ello se utilizaría un módulo didáctico de carácter audiovisual. El mismo, de no más de cinco minutos de duración, se vería en una pantalla LED y, también, estaría entres idiomas. Otro módulo que se emplearía sería un módulo didáctico de categoría gráfica y táctil sobre la cultura cristiana del primer tercio del siglo XVI. Los textos se acompañarían de un mapa del Reino de Valencia del siglo XVI, destacando los principales núcleos poblacionales, la Foia de Castalla y la provincia de Alicante. También habría un módulo didáctico de categoría informática y audiovisual, con pantalla táctil de grandes dimensiones. Su manipulación permitiría activar una pista de audio, en cualquiera de las tres lenguas citadas con anterioridad, en la que Rodrigo Vélez de la Huerta y Juan de la Miel hablarían sobre el contenido seleccionado, al tiempo que se proyectarían imágenes en una pantalla sobre el mismo y con la Foia de Castalla en la Edad Moderna.

Por último, el módulo expositivo Una nueva etapa en su vida, se situaría en la segunda planta del Palau y constaría de tres unidades temáticas. La primera, Un castillo que ya no funciona como castillo poseía, a su vez, dos unidades expositivas Abandono y Otros usos: militar, base escultórica y lugar de visita. En la primera, se abordaría los motivos que provocaron el abandono de la fortificación, se daría a conocer dicho proceso y se presentarían las consecuencias del mismo para la propia fortificación. Para ello, como recurso museográfico destacado se utilizaría un módulo didáctico de categoría audiovisual que recrearía la hipótesis más plausible de abandono del castillo: la pérdida de funcionalidad. Así, aparecerían los vasallos del señor recogiendo objetos, enseres, utensilios para su traslado a otra residencia de los Vilanova y cerrando las distintas partes del castillo. A partir de aquí se recreará la degradación progresiva de la fortificación hasta el siglo $\mathrm{XX}$, alternando con las palabras que escribieron personajes que visitaron Castalla durante los siglos XVIII y XIX. Su duración no superará los cinco minutos; mientras que su locución, y subtitulado, sería alterna en tres lenguas. En la segunda, se analizarían los nuevos usos de la fortificación durante las guerras de sucesión (1707-1713) e independencia (1808-1814), como base escultórica y como lugar frecuentado por las gentes de Castalla entre los siglos XVIII-XX. Para ello se utilizarán dos módulos didácticos de carácter informático y táctil, con mapas de la época, planos, libros en soporte original, fotografías, etc. Los mismos se complementarían con un módulo didáctico interactivo de categoría táctil en forma de maqueta tocable y realística de la Torre Grossa y el Sagrado Corazón de Jesús.

La segunda, Un castillo que sirve para conocer nuestro pasado, tendría, como base, la unidad expositiva Los primeros trabajos y las investigaciones en los años ochenta del siglo $X X$ explicaría los trabajos desarrollados en el castillo en los años treinta, cuarenta y ochenta del siglo XX. Los primeros por parte de aficionados, con las pérdi- 
das y destrucciones que ello conllevó y, los segundos, dentro de la Carta Arqueológica de la Foia de Castalla desarrollada por F. J. Cerdà i Bordera (1983) en el seno de la Universidad de Alicante. Esta unidad temática, también, se instalaría en la segunda planta del Palau.

Finalmente, en la tercera, La recuperación social del Castell de Castalla, ubicada en la planta baja de la Torre Grossa, se explicarían las actuaciones patrimoniales desarrolladas entre 1984 (estudios previos), 1997 y 1999 (excavación arqueológica del Palau y el Pati d'Armes), 2003-2006 (intervención arquitectónica), 2006-2017 (programa de visitas guiadas) y 2010-2017 (programa de conservación). En este caso, como módulo didáctico destacado se utilizarían un módulo interactivo de categoría audiovisual en tres lenguas, que permitirá conocer el proceso de recuperación de las manos de sus promotores científico y técnicos. De esta manera, el visitante podría seleccionar pistas en las que aparecería el equipo técnico explicando diversas cuestiones relacionadas con las actuaciones que ellos dirigieron. También habría con módulo con originales de los proyectos de intervención arqueológica, arquitectónica, estudios previos, etc.

Además de las dependencias internas del Palau y la Torre Grossa, sus respectivas terrazas también serían musealizadas. Al tratarse se excelentes miradores de la comarca, se aprovecharían para instalar una serie de módulos didácticos de categoría gráfica, en las lenguas ya citadas, para conocer los hitos paisajísticos de la comarca. Asimismo, en diferentes partes y elementos del Pati d'Armes, también se colocarían módulos didácticos gráficos de las mismas características para explicar el cuerpo de guardia del Pati d'Armes y las estancias musulmanas, el aljibe y la canalización de agua y la puerta de acceso.

\section{Conclusiones}

Dentro del Proyecto de recuperación social del Conjunt Patrimonial del Castell de Castalla, la musealización de la fortificación fue una de las líneas primordiales del trabajo con el objetivo de enriquecer el pobre panorama de fortificaciones musealizadas y reforzar y potenciar su papel turístico-cultural y didáctico, como contenedor cultu- ral, en el contexto de la provincia de Alicante y la Comunidad Valenciana. No obstante, y de manera paradójica, solo se abordó, al final del proyecto, por una decidida apuesta política. A pesar de todo, desde el primer momento se primó una musealización didáctica e interactiva, innovadora en el contexto de la provincia de Alicante, que favoreciera "el disfrute y el aprendizaje de la gente fuera de las aulas. Y en este sentido, la museografía didáctica e interactiva va por delante de la tradicional" (Mira, Bevià, Ortega, 2017, p. 434).

No obstante, la finalización del proyecto recuperación social, impidió contar con una musealización, novedosa, basada en secciones de interactivos especializados, en el contexto de la provincia de Alicante. De hecho, analizando la nueva musealización ejecutada, ésta es de carácter tradicional y repite el modelo de otros castillos de la zona como Atalaya (Villena), Banyeres de Mariola, Cocentaina, Dénia, Guardamar del Segura, Penella (Cocentaina), Petrer, Santa Bárbara y Sax. Por lo tanto, no puede decirse que destaque dentro del contexto de los 100 castillos de la Costa Blanca. Por ello, es inevitable pensar en la oportunidad perdida y que se ha seguido el camino fácil de repetir aquello que ya existe en lugar de innovar e intentar marcar la diferencia.

\section{Notas}

${ }^{1}$ Recientes investigaciones han permitido determina que el señor de Castalla fue Ramon de Vilanova i Montagut y no Ramon de Lladró de Vilanova i Vidaure, como se había creído tradicionalmente. La confusión se produjo porque se trata de personajes contemporáneos. 


\section{Bibliography}

Carrión Gútiez, A., coord. (2015). Plan Nacional de Arquitectura Defensiva, Ministerio de Educación, Cultura y Deporte, Madrid.

Martín Piñol, C.; Castell Villanueva, J. (2010). "Análisis y clasificación de los modelos interactivos", in Manual de museografía interactiva, Trea. Ed., Gijón, pp. 87-336.

Menéndez Fueyo, J.L.; Bevià i Garcia, M.; Mira Rico, J A.; Ortega Pérez, J.R. (2010). El Castell de Castalla. Arqueología, arquitectura e historia de una fortificación medieval de frontera, MARQ Ed., Alicante, p. 312.

Mira Rico, J.A. (2012). El Conjunto Patrimonial del Castell de Castalla. Una puerta abierta hacia su pasado. Guía de visita del Castell de Castalla, Ajuntament de Castalla Ed., Castalla, p. 24.

Mira Rico, J.A. (2016). "Castles or cultural and natural landscapes? A new approach to the managament of fortifications in the south of the Valencian Community (Spain). Examples of Castalla and Sax (Alicante)", in Cracow Landscape monographs, vol. 3. pp. 37-49.

Mira Rico, J.A. (2017). "Fortificaciones, interactividad y didáctica: el Castell de Castalla como ejemplo teórico en el contexto de la provincia de Alicante", OTARQ, 2. pp. 217-226.

Mira Rico, J.A.; Bevià i Garcia, M. (2016). De la Iglesia de Santa Maria a la Ermita de la Sang. Nuevas aportaciones para su conocimiento, Ajuntament de Castalla Ed., Castalla, p. 279.

Mira Rico, J.A.; Bevià i Garcia, M.; Ortega Pérez, J.R. (2015). "Del Castell de Castalla al Conjunt Patrimonial del Castell de Castalla: un nuevo enfoque en la gestión del patrimonio cultural valenciano", in FORTMED 2015. Defensive Architecture of the Mediterranean XV to XVIII Centuries, vol. I, pp. 367-374.

Mira Rico, J.A.; Bevià i Garcia, M.; Ortega Pérez, J.R. (2017). "La musealización del Castell de Castalla (Alicante, España). Un nuevo aporte para una situación pobre en el contexto de la provincia de Alicante", in FORTMED 2017. Defensive Architecture of the Mediterranean XV to XVIII Centuries, vol. VI, pp. 427-434.

Mira Rico, J.A.; Bevià i Garcia, M.; Ortega Pérez, J.R. (2018). "La musealización del patio y del almacén del Palau del Castell de Castalla (Alicante, España): nuevas aportaciones para el contexto de la provincia de Alicante", in FORTMED 2018. Defensive Architecture of the Mediterranean XV to XVIII Centuries, IX, pp. 1309-1316.

Mira Rico, J.A.; Carrión Marco, Y.; Morales-Pérez, J.V.; Ortega Pérez, J.R. (2017). "Nuevas aportaciones sobre el aprovechamiento faunístico y vegetal en el Castell de Castalla (Alicante, España) durante los siglos XI-XV", Arqueología y Territorio Medieval, 24, pp. 291-330.

Mira Rico, J.A.; Vilaplana Ortego, E.Mª.; Martínez Mira, I.; Bevià i Garcia, M.; Ortega Pérez, J.R. (2017). "Nuevas aportaciones para el conocimiento del Castell de Castalla (Alicante, España) a través del análisis de sus materiales pétreos, cerámicos, morteros y revestimientos", in FORTMED 2017. Defensive Architecture of the Mediterranean XV to XVIII Centuries, vol. V, pp. 381-388.

Rey Aynat, J.M. del; Ingeniería Belsanz S.L.; Hortelano Uceda, I. (2018). Proyecto básico y ejecución de adecuación y museización del Castell de Castalla y el acondicionamiento del aljibe y la vila medieval en Castalla. 4. Museología y Museografía. Memoria, guion de contenidos, pliego y guiones audiovisuales, (inédito).

Santacana i Mestre, J.; Hernàndez Cardona, F.X. (2011). Museos de historia. Entre la taxidermia y el nomadismo, Trea Ed., Gijón, p. 288. 